Article type: Article

\title{
Exploring the link between student placement learning in business organizations and self-employment preparatory behaviours
}

\section{Authors:}

Ugochukwu Chinonso Okolie

Alex Ekwueme Federal University Ndufu-Alike, Nigeria

Chinyere O. Elom

Alex Ekwueme Federal University Ndufu-Alike, Nigeria

\section{Godwin O. Onajite}

Ekiti State University, Nigeria

Sunday Okechukwu Abonyi

Ebonyi State University, Nigeria

Paul Agu Igwe

University of Lincoln, UK

Corresponding author:

Ugochukwu Chinonso Okolie, Alex Ekwueme Federal University Ndufu Alike, Department of Vocational and Technology Education, 6 Chief Jioke Ugo Street, Abakaliki, Ebonyi State 480213, Nigeria. Email: nonyeck@gmail.com

To cite this article Okolie, U. C., Elom, C. O., Onajite, G. O., Abonyi, S. O., Igwe, P. A. (2021). Exploring the link between student placement learning in business organizations and self-employment preparatory behaviours, Industry and Higher Education, https://doi.org/10.1177/09504222211057013 


\begin{abstract}
:
This study draws on social cognitive career theory to test a moderated mediation model of selfemployment preparatory behaviours in university students undertaking placement learning in a business organization (PLBO). Using data from 337 university students undertaking work placement in 123 business organizations, the study hypotheses were tested using PROCESS Macro 3.5. The results revealed that PLBO significantly influenced student self-employment selfefficacy, self-employment outcome expectations and self-employment preparatory behaviours. Also, self-employment self-efficacy and self-employment outcome expectations mediated the relationship between work placement learning and self-employment preparatory behaviours. However, placement supervisor support interacted with PLBO such that greater support from placement supervisors contributed to stronger self-employment preparatory behaviours. The placement learning supervisor support moderated the indirect effect of PLBO on self-employment preparatory behaviours via self-employment self-efficacy and self-employment outcome expectations at all levels ( $-1 \mathrm{SD}$, Mean and $+1 \mathrm{SD})$.
\end{abstract}

\title{
Keywords:
}

Work placement learning; supervisor support; social cognitive career theory; self-employment; self-efficacy; outcome expectations

\section{Introduction}

Although self-employment as a career choice has been widely researched in the literature (Douglas and Shephard, 2002; Caines et al., 2019), there is a need for further research on higher education students' self-employment preparatory behaviours (SPB) during PLBO. This study examines whether and how PLBO might influence student SPB and the psychological underlying mechanisms mediating and moderating such relationships. The study is timely given the call for university graduate self-employment research to promote job creation given the lack of jobs in light of the number of graduates produced yearly (Douglas and Shephard, 2002; Caines et al., 2019; Okolie et al., 2019; Okolie et al., 2021a; Tennant et al., 2018). SPB refers to important precursors of self-employment; it typically involves searching, planning, marshalling and organizing behaviours that students require to be self-employed after graduation (e.g., McGee et 
al., 2009). University students undertaking PLBO may engage in the initial phases of SPB, such as thinking about their future self-employment careers and setting self-employment goals.

Drawing on social cognitive career theory (SCCT) (Lent et al., 1994), career actions may be viewed as individuals' efforts toward achieving career goals; we thus operationalize career actions as SPB. However, students undertaking PLBO may form self-efficacy and outcome expectations around SPB, engage in preparatory behaviours, appraise their progress and then change their behaviours accordingly - depending on how well they perceive their progress to be (e.g., Okolie et al., 2021b; Sawitri and Creed, 2021). In the self-employment context, SCCT hypothesises that, before individuals begin any career-related activity, they go through a preparatory phase in which interest emerges. This preparatory phase may be seen as the conception stage that occurs before students take actions to be self-employed (Caines et al., 2019). While previous studies have investigated pre-venture stage behaviours in a nascent entrepreneurship context (e.g., Soutaris et al., 2007), further research is required to learn whether and how PLBO might influence SPB in the higher education context.

The concept of industrial work placement learning has generated interest in higher education settings, given its centrality to graduate employability and job creation (Bullock et al., 2009; Okolie et al., 2021b). Previous studies have focused more on work placement learning in general and its implications for careers and employability. However, we argue that during work placement learning programmes many students are sent to many business firms which may expose them to gaining business development skills and ignite their interest in becoming self-employed business owners. Thus, we conceptualize PLBO and refer to it as a planned skills development and employability enhancement programme of higher education institutions that offers students the opportunity to spend time gaining business development experiences in public or private business organisations to facilitate their decision-making about being self-employed (e.g., Douglas and Shephard, 2002; O’Donovan, 2018; Poulter and Smith, 2006). We argue that students sent to business firms for placement learning may be exposed to activities that motivate them to become self-employed rather than to enter paid employment. It is, therefore, important to investigate students undertaking PLBO to understand whether and how the associated activities might influence their SPB.

Universities around the world have attached high value to placement learning for its effectiveness in enhancing both the paid employment and self-employment prospects of graduates 
(Crawford and Wang, 2016; Crebert et al., 2004). Globally, the increasing pressure on universities to prepare students for both paid employment and self-employment after graduation has contributed to the inclusion of placement learning in the curriculum to enhance their intellectual development (Clark and Zukas, 2016) and their reflection on learning (Bullock et al., 2009) and to put theoretical concepts into practice (Aprile and Knight, 2020; Crawford and Wang, 2016). For example, in some countries, like the UK, placement schemes may be compulsory or voluntary and may last up to a year (Little and Harvey, 2006), whereas in Nigeria the placement scheme is a compulsory six-month programme for undergraduate students in business and management, science, technology, engineering and technology or vocational education (Industrial Training Fund, 2013). When assessed from a self-employment perspective, students undertaking a PLBO may develop interest in becoming self-employed and may therefore start the preparatory processes towards actualizing self-employment. Despite the emphasis on the perceived benefits of placement learning in previous literature (Bullock et al., 2009; Crawford and Wang, 2016), the links between a PLBO and SPB have received scant attention in the literature on higher education. We therefore contribute to the literature on placement learning by examining whether PLBOs might influence SPB and the psychological underlying mechanisms for such effects.

Given that SCCT "considers different levels of career progression that are adapted to the academic and professional circumstances of university students" (Lanero et al., 2016, p. 1055), and offers important variables that affect an individual's career choice in terms of self-efficacy and outcome expectations, we adapt the basic assumptions of SCCT to the field of self-employment as a career choice (e.g., Caines et al., 2019; Lanero et al., 2016). Self-efficacy denotes an individual's perceptions of his or her abilities to perform specific preparatory activities in order to succeed in the career choice of self-employment, whereas outcome expectations denote the outcomes of the individual's expectations about the consequences of the self-employment preparatory actions (e.g., Lent et al., 1994). Thus, we operationalize self-efficacy and outcome expectations as selfemployment self-efficacy and self-employment outcome expectations. Also, SCCT postulates that contextual factors (e.g., support, education, learning climate) may facilitate the development of self-efficacy and outcome expectations, which in turn influence the development of academic and career-related interests, goals and actions (Lent et al., 2002). In this light, we operationalize the contextual factors as PLBO and placement supervisor support (PSS). Consistent with SCCT, students who perceive PSS in the form of self-employment-related advice, information and 
feedback may consider SPB to be a crucial part of their lives and aspire to succeed in their future self-employment career choice (e.g., Lent et al., 2002).

PSS is important for students' undertaking a PLBO. Students need their supervisor's support to overcome possible barriers to the development of SPB (e.g., Sonntag et al., 2005; Van Gelderen et a., 2018). In this study, PSS refers to students' perceived help, encouragement, advice and guidance from placement supervisors in pursuing their self-employment career goals. We focus on PSS because placement supervisors are considered the most salient, influential and supportive individuals for students during a PLBO (Okolie et al., 2021a). This study therefore explores the nature of the underlying mechanisms via which a relationship between PLBO and SPB might exist. We focused on the SCCT framework; the core psychological variables (i.e., self-employment self-efficacy and self-employment outcome expectations) as mediating variables, contextual variables (i.e., PLBO as a predictor variable and PSS as a moderating variable), and career actions (i.e., SPB as the dependent variable). Using this framework, we examine a theory-driven moderated mediation model of PLBO and SPB and contribute to the literature on placement learning in higher education contexts.

\section{Theoretical and Hypotheses Development}

SCCT is an influential theory that may help to understand the influence of PLBO on SPB. Its core belief is on the three social cognitive variables of self-efficacy, outcome expectations and goals (Lent et al., 1994). SCCT provides helpful explanations of the intermediate stage between intentions and future career choice actions that are conducive to self-employment as a professional career (e.g., SPB). It explains that self-efficacy refers to a belief in one's ability to achieve a specific set of tasks and that people with high self-efficacy for certain tasks are more likely to pursue, persist with and accomplish their set goals than those with low self-efficacy (Lent et al., 2002). Also, Lent et al. (2002, p. 752) define outcome expectations as "beliefs about the consequences or outcomes of performing particular behaviours (e.g., what will happen if I do this?)". Outcome expectations involve what individuals expect from their behaviours, and motivate them to engage in such behaviours (McWhirter et al., 2000). In the context of PLBO, if students undertaking a PLBO realize that certain learning tasks or the determination of certain goals may help them to become self-employed after graduation, they are likely to be more willing to be part of such learning tasks due to their positive outcome expectations (Lent et al., 1994). Therefore, 
self-employment outcome expectations may stimulate behaviours toward becoming selfemployed.

\section{Linking WPL and SPB}

PLBO enables students to undertake normal job roles with organizations for a period of six months to one year (Poulter and Smith, 2006; Tennant et al., 2018). It is a special joint programme of universities and industry or business organizations designed to prepare students for paid employment or self-employment, and to equip them with the knowledge and motivation to pursue their employment goals after graduation. Drawing on the SCCT, PLBO is a contextual variable that may help us to understand students' SPB (Lent and Brown, 2013). Adapting the concept of SPB (Blau, 1994), we view SPB as the preparatory stage when students undertaking a PLBO contemplate their self-employment directions, gather useful information from their supervisors about the steps to take toward actualizing their self-employment career after graduation and think about the most strategic locations for their ventures to thrive. In this study, we examined the preparatory behaviours and operationalized them as activities that relate directly to preliminary SPB (Blau, 1994). Drawing on the SCCT choice model (Lent and Brown, 2013), we hypothesize that:

- Hypothesis 1: PLBO is positively associated with SPB.

\section{PLBO, Self-employment Self-efficacy and Self-employment Outcome Expectations}

In the course of students' development of SPB during PLBO, they may form self-employment self-efficacy and self-employment outcome expectations, which are compatible with SCCT (Lent et al., 1994). While SCCT has been widely applied to career choice research, many recent studies have applied it to the formation of entrepreneurial behaviours (e.g., Lanero et al., 2016), and have found that students may develop self-efficacy and outcome expectations beliefs that can influence their self-employment or entrepreneurial intentions. For example, when students develop important self-employment-related skills through PLBO, they may develop self-employment selfefficacy and self-employment outcome expectations, and the formation of these two psychological variables may, in turn, influence their SPB (Kolvereid, 1996; McGee et al., 2009). Relying on SCCT assumptions, we hypothesize that: 
- Hypothesis 2: PLBO is positively associated with (a) self-employment self-efficacy and (b) self-employment outcome expectations.

- Hypothesis 3: (a) self-employment self-efficacy and (b) self-employment outcome expectations are positively associated with SPB.

- Hypothesis 4: (a) self-employment self-efficacy and (b) self-employment outcome expectations mediate the relationship between PLBO and SPB.

\section{Moderating Effect of Placement Supervisor Support (PSS)}

In the SCCT framework, social support is an important resource that has shown influence on individuals' career preparation, work-related behaviours and planning (Lent and Brown, 2013). Also, PSS may motivate students undertaking a PLBO to engage in pre-venture behaviours or SPB such as searching, planning and marshalling for a successful self-employment career after graduation (McGee et al., 2009), and so strengthen their self-employment self-efficacy, selfemployment outcome expectations and SPB. Also, PSS can strengthen students' learning experience given that they may regard their supervisors as role models, and build trust and relationships throughout their stay in the placement organization. Such positive relationships between students and their supervisors during a PLBO may mitigate the effect of potential obstacles to students' self-employment career progress. Students who experience challenges in developing important skills and knowledge for future self-employment career goals may feel equipped to overcome the challenges if they perceive adequate PSS (Okolie et al., 2021). This corroborates SCCT's perspective on the possible role of contextual factors (e.g., support) in strengthening the relationship between PLBO and SPB (e.g., Lent and Brown, 2013). Drawing on SCCT, we hypothesize that:

- Hypothesis 5: The interaction between PSS and PLBO on (a) self-employment selfefficacy, (b) self-employment outcome expectations, and (c) SPB is positive and significant, such that the effects are stronger when PSS is high than when it is low. 
Combining Hypotheses 1-5 implies a moderated mediation model, which proposes that the indirect effect of PLBO on SPB is transmitted via self-employment self-efficacy and selfemployment outcome expectations and that the indirect effects are contingent on the level of PSS (Hayes, 2018b). Against this backdrop, we propose the following moderated mediation model (Figure 1) and hypothesize that:

- Hypothesis 6: PSS moderates the indirect effect of PLBO on SPB via (a) self-employment self-efficacy and (b) self-employment outcome expectations, and these relationships are conditional on the level of PSS.

\section{INSERT FIGURE 1 ABOUT HERE}

\section{Method}

Sample and Procedures

All students in this study were in various months of PLBO in 123 business organizations in Nigeria. The business sectors included production and repair, sales and marketing, media and advertising, hospitality industry, real estate, financial institutions, transportation, agriculture, oil and gas, leasing and power/electricity. Ethical approval was obtained from the organizations and participants gave consent to participate in the study with the assurance of anonymity and confidentiality. The participants were identified through a face-to-face approach in their various organizations and were randomly selected. Using a three time point data collection approach, data were collected from the same respondents at three different time points to avoid the problem of common method bias associated with self-reporting (Podsakoff et al., 2003). The rationale for collecting data at three time points was to ensure that only responses that were consistent across the three time points were used for data analysis.

At Time one (T1), 529 copies of the questionnaire for data collection were distributed to participants, who willingly agreed to complete them and hand them in to the researcher face-toface. We coded completed questionnaires using 4-digit numbers formulated to help us match the responses across the three-time point data collection processes. At T2 (after a 4-week interval) copies of the questionnaire were given to the same respondents to complete, and the response rate 
dropped to 501 (94.71\%). At T3 (after another 4 weeks), the same participants who responded at both $\mathbf{T} 1$ and $\mathbf{T} 2$ were given copies of the same questionnaire to complete face-to-face, and the response rate dropped to $483(91.30 \%)$. The drop in the response rate was because some participants had in the meantime completed their placement programme and returned to their campus. In the three time point data collections, the same participants responded to the same questionnaire containing PLBO, self-employment self-efficacy, self-employment outcome expectations and SPB scales. We matched their responses and removed 146 responses due to inconsistency in responses at T1, T2 and T3. Thus, a sample of 337 (63.71\% matched responses) was used for the final dataset. Among these participants were 216 (64.10\%) males and 121 (35.90\%) females between the ages of 19 and 25.

Measures

Work Placement Learning in Business Organizations. We adapted 10 items from the 13-item internship-related learning outcomes scale (Nghia and Duyen, 2019), and reworded 'internships' in the original scale as placement learning in business organizations. Responses ranged from 1 (= very little) to 5 (= very much). A sample item includes: "The placement learning gives me opportunities to become acquainted with some potential business partners". In the present study, the scale was subjected to one-factor confirmatory factor analysis (CFA) using AMOS 24.0. We kept the focus on the content of the items and gradually removed 3 items that loaded below the 0.70 recommended value (Hair et al., 2010). A CFA model with the remaining 7 items yielded a good data fit: $\chi^{2}=48.30 ; \mathbf{d f}=35 ; \chi^{2} / \mathbf{d f}=1.38$; $\mathrm{CFI}=0.97$; TLI $=0.95$; GFI $=$ 0.96 ; $\mathrm{SRMR}=0.03, \mathrm{RMSEA}=0.05$ with the following reliability and validity values: composite reliability $(\mathrm{CR})=0.94$, average variance extracted $(\mathrm{AVE})=0.79$, discriminant validity $(\mathrm{DV})=$ 0.89 , maximum shared variance $(\mathrm{MSV})=0.01$, and Cronbach's alpha $(\alpha)=0.95(\mathrm{Hu}$ and Bentler, 1999).

Placement Supervisor Support. We used the 4-item Learning Culture Inventory which includes the "Learning Orientated Executive Tasks" scale (Sonntag et al., 2005), and which has been adapted in previous research (Decius et al., 2021). Responses ranged from 1 (= strongly disagree) to 5 (= strongly agree). A sample item includes: "My supervisor supports me in taking advantage of 
personnel development opportunities." The Cronbach's alpha for the original scale was 0.90. The CFA for the one-factor model yielded a good data fit: $\chi^{2}=6.84 ; \mathrm{df}=4 ; \chi^{2} / \mathrm{df}=1.71 ; \mathrm{CFI}=0.98$; $\mathrm{TLI}=0.96 ; \mathrm{GFI}=0.97 ; \mathrm{SRMR}=0.04, \mathrm{RMSEA}=0.06$ with the validity and reliability values: $\mathrm{CR}$ $=0.92, \mathrm{AVE}=0.77, \mathrm{MSV}=0.02, \mathrm{DV}=0.87$ and Cronbach's $\alpha=0.93$ (Hair et al., 2010; Hu and Bentler, 1999).

Self-employment Self-efficacy. The study adopted the "Pre-venture Activities Scale" (McGee et al., 2009), focusing on the pre-venture activities sub-scale which consisted of 10 items. Responses ranged from 1 (= strongly disagree) to 5 (= strongly agree). A sample item includes: "I feel able to design a product or service that will satisfy customer needs and wants." The original scale had the following Cronbach's alphas: searching $=0.84$; planning $=0.84$ and marshalling $=0.80$. The sub-scales were merged into a single variable to measure self-employment self-efficacy during CFA. The one-factor model yielded a good data fit: $\chi^{2}=72.45 ; \mathrm{df}=35 ; \chi^{2} / \mathrm{df}=2.07$; CFI = 0.95; TLI = 0.94; GFI = 0.92; SRMR = 0.05, RMSEA $=0.07$ with validity and reliability values: $\mathrm{CR}=0.89, \mathrm{AVE}=0.74, \mathrm{MSV}=0.12, \mathrm{DV}=0.86$ and Cronbach's $\alpha=0.90$ (Hair et al., 2010; Hu and Bentler, 1999).

Self-employment Outcome Expectations. In line with the notion that outcome expectations are concerned with imagined consequences of a particular task (Lent and Brown, 2006), we adapted a 6-item "Career Outcome Expectations Scale" (McWhirter et al., 2000). Responses ranged from 1 (= strongly disagree) to 4 (= strongly agree). A sample item includes: "I will be successful in my chosen self-employment as a career/occupation." The original scale had a Cronbach's alpha of 0.83. In the present study, the one-factor CFA showed a good data fit: $\chi^{2}=15.21$;f $=9 ; \chi^{2} / \mathrm{df}=$ 1.69; $\mathrm{CFI}=0.98 ; \mathrm{TLI}=0.96 ; \mathrm{GFI}=0.95 ; \mathrm{SRMR}=0.03, \mathrm{RMSEA}=0.05$ with validity and reliability values: $\mathrm{CR}=0.91, \mathrm{AVE}=0.71, \mathrm{MSV}=0.02, \mathrm{DV}=0.84$ and Cronbach's $\alpha=0.92(\mathrm{Hu}$ and Bentler, 1999).

Self-employment Preparatory Behaviours. Drawing on the perspectives of SCCT (Lent and Brown, 2006), we adapted the 3 entrepreneurial (self-employment) intentions scale (Kolvereid, 1996), and 4 nascent behaviours scale (McGee et al., 2009) which addressed preparatory behaviours. Responses ranged from 1 (=strongly disagree) to 7 (=strongly agree). Previous studies (e.g., Lanero et al., 2016), have merged the two scales to measure a single variable - 
entrepreneurial career choice. A sample item includes "I am gathering resources to start a business/become self-employed". The 7 items were used for the one-factor model in CFA, which showed a good data fit: $\chi^{2}=28.14 ; \mathrm{df}=14 ; \chi^{2} / \mathrm{df}=2.01 ; \mathrm{CFI}=0.96$; TLI $=0.95 ;$ GFI $=0.93$; $\mathrm{SRMR}=0.05, \mathrm{RMSEA}=0.07$ with validity and reliability values: $\mathrm{CR}=0.82, \mathrm{AVE}=0.61, \mathrm{MSV}$ $=0.21, \mathrm{DV}=0.78$, Cronbach's $\alpha=0.83$ (Hair et al., 2010; Hu and Bentler, 1999). However, we controlled for age, gender and length of stay in the placement programme to learn their effects on SPB.

\section{Results}

\section{Preliminary Analysis}

Table 1 shows the results of bivariate correlations among the variables. PLBO was positively correlated with SPB $(r=0.32, p<0.01)$, self-employment self-efficacy $(r=0.34, p<0.01)$ and self-employment outcome expectations $(r=0.39, p<0.01)$. Also, self-employment self-efficacy $(r=0.46, p<0.01)$ and self-employment outcome expectations $(r=0.41, p<0.01)$ positively correlated with SPB, indicating possible mediation effect (Hayes, 2018a). The analysis showed no evidence of a significant correlation between PLBO and PSS ( $r=0.04, p=0.24)$, indicating that the moderator (PSS) served as an auxiliary variable to explain a causal relationship, and does not correlate with the independent variable (Wu and Zumbo, 2008). The correlation coefficients showed no evidence of strong multicollinearity as the test of condition indices and variance inflation factors ranged from 1.07 to 2.81 , confirming no problem with multicollinearity in our data (Belsley et al., 1980). Also, the results of the univariate skewness and kurtosis for each item ranged from -1.41 to 0.15 and -0.51 to 3.11 , respectively confirming that the participants' responses were normally distributed (Kline, 2015).

\section{INSERT TABLE 1 ABOUT HERE}

\section{Testing the Unmoderated Direct and Indirect Effects}

Hypotheses 1, 2, 3 and 4 were tested using Hayes-PROCESS Macro 3.5. Following the guidelines by Hayes (2018a), we selected "Model 4" in the options menu, and applied 10000 bootstrap samples at $95 \%$ bias-corrected confidence intervals to compute the unmoderated direct and indirect effects (including covariates) concurrently. As shown in Figure 2, PLBO was associated positively 
with SPB $(\beta=0.11, p<0.03)$, indicating that Hypothesis 1 was accepted. The results for Hypotheses $2 \mathrm{a}$ and $2 \mathrm{~b}$ showed that PLBO was associated positively with self-employment selfefficacy $(\beta=0.34, p<0.001)$ and self-employment outcome expectations $(\beta=0.39, p<0.001)$, indicating that these hypotheses were accepted. The analysis showed that self-employment selfefficacy $(\beta=0.28, p<0.001)$ and self-employment outcome expectations $(\beta=0.31, p<0.001)$ were positively associated with SPB; hence, Hypotheses $3 \mathrm{a}$ and $3 \mathrm{~b}$ were accepted. The results for Hypotheses $4 \mathrm{a}$ and $4 \mathrm{~b}$ showed that self-employment self-efficacy $\left(\beta=0.07, \mathrm{CI}_{95}: 0.03,0.12\right)$ and self-employment outcome expectations $\left(\beta=0.09, \mathrm{CI}_{95}: 0.05,0.14\right)$ mediated the PLBO and SPB relationship, indicating that these hypotheses were accepted. However, the regression analysis showed no evidence of a significant influence on SPB of age $(\beta=0.03, p=0.19)$ or gender $(\beta=$ $0.07, p=0.25)$, but length of stay in the placement programme did have a significant influence $(\beta=0.20, p<0.001)$ on SPB.

\section{INSERT FIGURE 2 ABOUT HERE}

\section{Testing the Conditional Direct and Indirect Effects}

Hypotheses 5 and 6 focus on the moderated mediation analysis. Thus, we followed the procedures for analysing the conditional relationships (Preacher et al., 2007; Hayes, 2018b), selected "Model 8" in the options menu of the Hayes-PROCESS Macro 3.5, and applied 10000 bootstrap samples at $95 \%$ bias-corrected confidence intervals. PSS was included in the " $W$ " options menu to test the type of moderated mediation model depicted in Figure 1. As also shown in Figure 2 (hypotheses5a, 5b and 5c), the interaction effect of PLBO $x$ PSS on the selfemployment self-efficacy path was positive $(b=0.03, p<.001)$ with a significant model summary; $F_{(3,333)}=17.71, p<0.001, \mathrm{R}^{2}=0.14$ and a test of highest order unconditional interaction; $F_{(1,333)}$ $=8.61, \Delta \mathrm{R}^{2}=0.02, p<0.001$. The interaction effect of PLBO $x$ PSS on the self-employment outcome expectations path was positive $(b=0.02, p<0.001)$ with a significant model summary; $F_{(3,33)}=22.11, p<0.001, \mathrm{R}^{2}=0.17$ and a significant test of highest order unconditional interaction; $F_{(1,333)}=5.79, \Delta \mathrm{R}^{2}=0.01, p<0.001$. The interaction effect of PLBO $x$ PSS on the SPB direct path was positive $(b=0.04, p<0.001)$ with a significant model summary; $F_{(4,332)}=$ $30.21, P<.001, \mathrm{R}^{2}=0.27$ and a significant test of highest order unconditional interaction; $F_{(1,332)}$ $=14.35, \Delta \mathrm{R}^{2}=0.03, p<0.001$. These results indicate that PSS moderated the effect of PLBO on 
both the mediators (self-employment self-efficacy and outcome expectations) and direct (SPB) paths. Thus, we accepted Hypotheses 5a, 5b and 5c.

\section{INSERT TABLE 2 ABOUT HERE}

Figures 3, 4 and 5 show the simple slopes for the visualization of the conditional direct effects at 3 points (-1SD, Mean, +1SD) along the scale of PSS (Hayes, 2018b). To the self-employment self-efficacy path (Figure 3), the analysis showed that at-1SD on PSS, the effects of PLBO were positive $\left(b_{\text {slope }}=0.17, p<.001\right)$ at the Mean $\left(b_{\text {slope }}=0.28, p<0.001\right)$, and at $+1 \mathrm{SD}\left(b_{\text {slope }}=0.40\right.$, $p<0.001$ ). To the self-employment outcome expectations path (Figure 4), the effect of PLBO was positive at $-1 \mathrm{SD}$ on PSS; $\left(b_{\text {slope }}=0.21, p<0.001\right)$, at the Mean $\left(b_{\text {slope }}=0.30, p<0.001\right)$ and at $+1 \mathrm{SD}\left(b_{\text {slope }}=0.39, p<0.001\right)$. Figure 5 shows the simple slopes of the conditional effect of PLBO on SPB path: at $-1 \mathrm{SD}$ on PSS, the effect was not positive $\left(b_{\text {slope }}=0.01, p=0.77\right)$, while the at Mean $\left(b_{\text {slope }}=0.14, p<0.001\right)$ and at $+1 \mathrm{SD}\left(b_{\text {slope }}=0.27, p<0.001\right)$, the effects were positive (see Table 2).

\section{INSERT FIGURES 3, 4 AND 5 ABOUT HERE}

As shown in Table 2, the conditional indirect effect of PLBO on SPB via self-employment self-efficacy was positive at $-1 \mathrm{SD}(\beta=0.05, \mathrm{CI} 95: 0.01,0.10)$, at the Mean $\left(\beta=0.09\right.$, $\mathrm{CI}_{95}: 0.04$, $0.14)$ and at $+1 \mathrm{SD}\left(\beta=0.13\right.$, CI $\left._{95}: 0.06,0.21\right)$. The conditional indirect effect of PLBO on SPB via self-employment outcome expectations was positive at $-1 \mathrm{SD}\left(\beta=0.08, \mathrm{CI}_{95}: 0.03,0.13\right)$, at the Mean $\left(\beta=0.11, \mathrm{CI}_{95}: 0.06,0.17\right)$ and at $+1 \mathrm{SD}\left(\beta=0.14, \mathrm{CI}_{95}: 0.07,0.22\right)$.

For the index of moderated mediation analysis, the Omnibus tests of conditional indirect effect showed in the index of moderated mediation of PLBO on SPB at 95\% bootstrap confidence intervals (Hayes, 2018b; Preacher et al., 2007) were positive and significant for the PLBO selfemployment self-efficacy ( $\left.b_{\text {Index }}=0.01, S E=0.00, \mathrm{CI}_{95}: 0.01,0.02\right)$ and self-employment outcome expectations paths $\left(b_{\text {Index }}=0.01, S E=0.00, \mathrm{CI}_{95}: 0.01,0.03\right)$. These results indicate that the indirect effects were conditional on the level of PSS. Thus, Hypotheses $6 \mathrm{a}$ and $6 \mathrm{~b}$ were accepted.

\section{Discussion}

This study examines how PLBO might influence university students' SPB. It builds on SCCT to test a theory-driven moderated mediation model of PLBO, PSS, self-employment self-efficacy, 
outcome expectations, and SPB. The strength of the study lies in its reliance on the SCCT framework to test all the hypotheses and the robust analysis conducted to test the moderated mediation model. It makes an innovative contribution to the self-employment literature, given the scarce research into interactions among SCCT's contextual factors (PSS and PLBO) and the core SCCT variables of self-efficacy and outcome expectations on SPB.

The findings establish that PLBO influenced students' SPB in this population (Hypothesis 1). This result was expected, given the widely positive reports of placement learning and its implications for career behaviour (Caspersen and Smeby, 2020; Okolie et al., 2021a). However, the finding serves as a baseline hypothesis, of which confirmation in the present study is necessary. Our findings reveal that PLBO influenced students' self-employment self-efficacy and selfemployment outcome expectations (Hypotheses $2 \mathrm{a}$ and $2 \mathrm{~b}$ ). These results imply that students undertaking a PLBO may be more likely to form self-employment self-efficacy and selfemployment outcome expectations toward SPB. The findings suggest that undertaking a PLBO can help students to build self-efficacy in performing SPB which may lead to actual selfemployment after graduation (agrees with Lent and Brown, 2013; McGee et al., 2009; Okolie et al., 2021b).

We found that self-employment self-efficacy and self-employment outcome expectations influenced students' SPB during PLBO in this population (Hypotheses 3a and 3b). These results validate the SCCT perspective and show that the more self-employment self-efficacy and selfemployment outcome expectations students form during PLBO, the higher their SPB. In line with the hypotheses, self-employment self-efficacy and outcome expectations have a direct effect on SPB, which confirms SCCT's position that self-efficacy and outcome expectations can predict individuals' career behaviours properly (Lent et al., 1994). The results could also be interpreted as showing that students' self-employment self-efficacy and expectations of future positive results during PLBO could make them engage more in SPB. The finding agrees with that of Lanero et al. (2016, p. 1) who also noted that "self-efficacy exerted positive effects on outcome expectations, entrepreneurial interests, and career choice, which holds for students across disciplines". We found that self-employment self-efficacy and self-employment outcome expectations mediated the PLBO and SPB relationship (Hypotheses $4 \mathrm{a}$ and $4 \mathrm{~b}$ ). These findings imply that PLBO may not be the only reason for the increased SPB but that it may also be due to self-employment self-efficacy 
and outcome expectations which students develop as they undertake PLBO (consistent with Lent et al., 2002).

The findings also show that PSS interacts with PLBO such that higher PSS contributes to higher SPB (Hypothesis 5). The results reveal that PSS strengthened the increasing effects of PLBO, self-employment self-efficacy and outcome expectations on SPB. This could mean that the interaction effect of PSS on the self-employment efficacy and self-employment outcome expectation paths was significant and positive at low, average and high levels. However, on the PLBO and SPB direct path, the results show no evidence of a positive conditional effect of PSS and PLBO when the PSS was low; rather, the effects were positive when PSS was average and high. This result is consistent with the SCCT perspective and indicates that, although students undertaking a PLBO may rely more on their supervisors for self-employment-related advice or information, a low level of PSS may not have a positive direct effect on students' SPB, as opposed to average and high levels of PSS.

Regarding the conditional indirect effect of PLBO on SPB via self-employment selfefficacy and self-employment outcome expectations as moderated by PSS (Hypothesis 6), we found that the indirect effect was strengthened at low, average and high levels (-1SD, Mean and $+1 \mathrm{SD})$. Linked to SCCT, adequate support from students' learning environments such as the workplace during PLBO can strengthen or increase their ability to translate their interests into actions (i.e., SPB) (Lent et al., 1994). Our findings indicate that self-employment self-efficacy and outcome expectations were positive and significant in students with various levels of PSS, despite the quality of PLBO, whereas, PLBO can bolster students' SPB directly when the levels of PSS are average and high.

\section{Conclusion and Implications}

This study is, to our knowledge, the first to examine a theory-driven moderated mediation model of PLBO, PSS, self-employment self-efficacy, self-employment outcome expectations and SPB, and contributes to theory and practice. It contributes to our understanding of students' SPB during PLBO, adding to the growing body of SCCT research concerning higher education students undertaking PLBO and SPB (Caines et al., 2019; Crebert et al., 2004; Douglas and Shepherd, 2002; Okolie et al., 2019; Poulter and Smith, 2006). Our findings support the applicability of SCCT to PLBO and SPB, revealing that higher education students can develop self-employment career 
interests, and engage in preparatory behaviours in which they form self-efficacy and outcome expectations (Lent et al., 1994). Our findings contribute to SCCT by demonstrating that an essential placement-related contextual factor (i.e., PSS) interacted with another contextual factor (i.e., PLBO) to increase students' self-employment self-efficacy and outcome expectations, which in turn influenced SPB.

The findings have practical implications for supervisors of PLBO, policymakers and university administrators, as well as for students. First, the results can be beneficial to university administrators and policymakers in that they highlight how good-quality PLBO programmes can facilitate students' SPB leading to self-employment after graduation. Thus, they can also support the government's move towards encouraging graduates to be self-employed (Okolie et al., 2019). The findings highlight the importance of adequate PSS for students undertaking a PLBO to strengthen their self-employment self-efficacy and outcome expectations, and in turn strengthen their SPB (Lanero et al., 2016; McGee, 2009). Policymakers and practitioners working to promote graduate self-employment can benefit from the findings. Furthermore, universities and businesses sending and accepting students for PLBO might place more emphasis on PSS with a view to improving the quality of PLBO and students' SPB.

\section{Limitations and Directions of Future Research}

We acknowledge some limitations of the study. The first concerns the homogeneity of the participants, who were university students undertaking a PLBO. This may limit the generalizability of the findings to other students who undertake a PLBO. We suggest that future studies should replicate this study with students from other institutions of higher learning in other countries to understand the effects. Another potential limitation is the use of adapted scales not specifically designed and validated to examine SPB, self-employment self-efficacy and self-employment outcome expectations among students. We recommend that future studies should look towards this direction. Regarding the sample size, we minimized the limitation by applying a 10000 resample bootstrapping method to allow for generalization of the findings (Hayes, 2018a). Despite collecting data at three time points to avoid the problems associated with self-report measures, it may not wholly allow the establishment of causality. Therefore, we recommend that future studies should use a longitudinal or experimental research approach to replicate this 
study in other contexts. While the study was conducted in Nigeria, the findings should also be of interest to other countries.

\section{References}

Aprile K T, and Knight B A (2020) The WIL to learn: Students' perspectives on the impact of work-integrated learning placements on their professional readiness. Higher Education Research \& Development 39(5): 869-882 1-14. doi:10.1080/07294360.2019.1695754

Belsley D A, Kuh E and Welsch RE (1980) Regression diagnostics. New York: John Wiley \& Sons.

Blau G, (1994) Testing a two-dimensional measure of job search behavior. Organizational Behaviour and Human Decision Processes 59: 288-312.

Bullock K, Gould V, Hejimadi M, and Lock G (2009) Work placement experience: Should I stay or should I go? Higher Education Research and Development 28(5): 481-94.

Caines V, Earl JK, and Bordia P (2019) Self-employment in later life: How future time perspective and social support influence self-employment interest. Frontiers in Psychology 10(448): $1-13$.

Caspersen J and Smeby J (2020) Placement training and learning outcomes in social work education. Studies in Higher Education, https://doi.org/10.1080/03075079.2020.1750583

Clark M and Zukas M (2016) Understanding successful sandwich placements: a Bourdieusian approach. Studies in Higher Education 41(7): 1281-1295.

Crebert G, Bates M, Bell B, Patrick C, and Cragnolini V (2004) Developing generic skills at university, during work placement and in employment: Graduates' perceptions. Higher Education Research \& Development 23(2): 147-165.

Crawford I and Wang Z (2014) The impact of placements on the academic performance of UK and international students in higher education. Studies in Higher Education 41(4): 712733.

Douglas E J, and Shepherd D A (2002) Self-employment as a career choice: Attitudes, entrepreneurial intentions, and utility maximization. Entrepreneurship Theory and Practice, 26(3): 81-90.

Hair J, Black W, Babin B, and Anderson R (2010) Multivariate data analysis. (7th ed.): PrenticeHall, Inc. Upper Saddle River, NJ, USA. 
Hayes A.F. (2018a) Introduction to mediator, moderation, and conditional process analysis: A regression-based approach. (2nd ed.). Guilford Publications, New York, NY.

Hayes AF (2018b) Partial, conditional, and moderated moderated mediation: Quantification, inference, and interpretation. Communication Monographs 85(1): 4-40.

$\mathrm{Hu}$ L, and Bentler PM (1999) Cutoff criteria for fit indexes in covariance structure analysis: Conventional criteria versus new alternatives. Structural Equation Modelling 6(1): 1-55.

Industrial Training Fund (2013) Information and guidelines for student's industrial work experience scheme for developing the Nations Human resources. ITF Press.

Kline R B (2015) Principles and practice of structural equation modeling. Guilford Press.

Kolvereid L (1996) Prediction of employment status choice intentions. Entrepreneurship Theory and Practice 21(1): 47-58.

Lanero A, Vázquez JL, and Aza CL (2016) Social cognitive determinants of entrepreneurial career choice in university students. International Small Business Journal 34(8): 1053-1075.

Lent RW and Brown SD (2013) Social cognitive model of career self-management: Toward a unifying view of adaptive career behavior across the life span. Journal of Counseling Psychology 60: 557-568.

Lent RW, Brown SD and Hackett G (2002) Social cognitive career theory. In Brown, D. (Ed.), Career Choice and Development. Jossey-Bass

Lent RW, Brown SD and Hackett G (1994) Toward a unifying social cognitive theory of career and academic interest, choice, and performance. Journal of Vocational Behavior 45: 79122.

McGee JE, Peterson M, Mueller SL, and Sequeira JM (2009) Entrepreneurial self-efficacy: Refining the measure. Entrepreneurship Theory and Practice 33(4): 965-988.

McWhirter EH, Rasheed S, and Crothers M (2000) The effects of high school career education on social cognitive career variables. Journal of Counseling Psychology 47: 330-341.

Nghia TLH and Duyen T M (2019) Developing and validating a scale for evaluating internshiprelated learning outcomes. Higher Education 77: 1-18

O’Donovan D (2018) Bilateral benefits: Student experiences of work-based learning during work placement. Industry and Higher Education 32(2): 119-128.

Okolie UC, Ochinanwata C, Ochinanwata N, Igwe PA and Okorie GO (2021a) Perceived supervisor support and learner's career curiosity: The mediating effect of sense of 
belonging, engagement and self-efficacy. Higher Education, Skills and Work-Based Learning. https://doi.org/10.1108/HESWBL-09-2020-0207

Okolie UC, Nwajiuba C A, Eneje B, Binuomote MO, Ehiobuche C, and Hack-Polay D (2021b) A critical perspective on industry involvement in higher education learning: Enhancing graduates' knowledge and skills for job creation in Nigeria. Industry and Higher Education 35(1): 61-72.

Okolie UC, Nwosu HC and Mlanga S (2019) Graduate employability: How the higher education institutions can meet the demands of the labour market. Higher Education, Skills and WorkBased Learning 9(4): 620-636.

Podsakoff PM, MacKenzie SB, Lee JY and Podsakoff N P (2003) Common method biases in behavioral research: A critical review of the literature and recommended remedies. Journal of Applied Psychology 88(5): 879-903.

Poulter E and Smith B (2006) A work placement review from an undergraduate's perspective, Planet 16(1): 43-45.

Preacher KJ, Rucker DD and Hayes AF (2007) Addressing moderated mediation hypotheses: Theory, methods, and prescriptions. Multivariate Behavioral Research 42: 185-227.

Sawitri DR and Creed PA (2021) Adolescent-parent career congruence as a predictor of job search preparatory behaviors: The role of proactivity. Journal of Career Development 1-16. https://doi.org/10.1177/0894845321992548

Smith R and Hodge S (2019) Understanding innovation through the vocational student workplacement experience. Journal of Workplace Learning 31(7): 409-428.

Sonntag K, Schaper N and Friebe J (2005) Erfassung und Bewertung von Merkmalen unternehmensbezogener Lernkulturen [Assessment and evaluation of characteristics of company-related learning cultures]. In Arbeitsgemeinschaft Betriebliche Weiterbildungsforschung e. V. / Projekt Qualifikations- Entwicklungs-Management (Ed.), Kompetenzmessung im Unternehmen. Lernkultur- und Kompetenzanalysen im betrieblichen Umfeld (pp. 19-339). Munster, New York, Munchen, Berlin: Waxmann.

Souitaris V, Zerbinati S and Al-Laham A (2007) Do entrepreneurship programmes raise entrepreneurial intention of science and engineering students? The effect of learning, inspiration and resources. Journal of Business Venturing 22(4): 566-591. 
Tennant S, Murray M, Gilmour B and Brown L (2018) Industrial work placement in higher education. Industry and Higher Education 32(2): 108-118.

Van Gelderen I, Matthew SM, Hendry GD and Taylor R (2018) Variation in clinical placement supervisors' conceptions of and approaches to supervision in a veterinary internship programme. Higher Education Research \& Development 37(2): 418-432.

Wu AD and Zumbo BD (2007) Understanding and using mediators and moderators. Social Indicators Research 87(3): 367-392. 
Table 1. Mean, Standard Deviation, and Bivariate Correlations among Variables.

\begin{tabular}{|c|c|c|c|c|c|c|c|c|c|c|}
\hline & & Mean & SD & 1 & 2 & 3 & 4 & 5 & 6 & 7 \\
\hline 1 & Age & 1.66 & 0.48 & 1 & & & & & & \\
\hline 2 & Gender & 1.45 & 0.49 & $-0.24 * *$ & 1 & & & & & \\
\hline 3 & $\begin{array}{l}\text { Length of Stay in Placement Learning } \\
\text { Placement Learning in Business }\end{array}$ & 1.60 & 0.49 & 0.08 & -0.03 & 1 & & & & \\
\hline 4 & Organizations & 11.03 & 3.91 & 0.03 & 0.03 & 0.07 & 1 & & & \\
\hline 5 & Placement Supervisor Support & 10.72 & 3.65 & -0.06 & 0.04 & 0.02 & 0.04 & 1 & & \\
\hline 6 & Self-employment Outcome Expectations & 11.23 & 2.98 & 0.01 & $-0.12 *$ & 0.03 & $0.39 * *$ & -0.03 & 1 & \\
\hline 7 & $\begin{array}{l}\text { Self-employment Self-efficacy } \\
\text { Self-employment Preparatory }\end{array}$ & 11.92 & 3.19 & 0.04 & -0.01 & -0.06 & $0.34 * *$ & -0.02 & $0.41^{* *}$ & 1 \\
\hline 8 & Behaviours & 12.2 & 2.95 & 0.02 & 0.08 & $0.20 * *$ & $0.32 * *$ & -0.03 & $0.46^{* *}$ & $0.43^{* *}$ \\
\hline
\end{tabular}

Table 2. Conditional Direct and Conditional Indirect Effects. 
Conditional effects of the moderator (PLBO x PSS) on selfemployment self-efficacy path

Low (-1SD)

Average (Mean)

High (+1SD)

Conditional effects of the moderator (PLBO $x$ PSS) on self-

employment outcome expectations path

Low (-1SD)

Average (Mean)

High (+1SD)

Conditional effects of the moderator (PLBO $x$ PSS) on self-

employment preparatory behaviours path

Low (-1SD)

Average (Mean)

High (+1SD)

\section{Conditional Indirect Effects}

$\mathrm{PLBO} \rightarrow$ Self-employment self-efficacy $\rightarrow$ SPB

Low $(-1 \mathrm{SD})$

Average (Mean)

High (+ 1SD)

$0.21 * * * \quad 0.05$

$0.30 * * *$

$0.39 * * *$

0.04

0.05

4.13

PLBO $\rightarrow$ Self-employment Out. Expec. $\rightarrow$ SPB

Low $(-1 \mathrm{SD})$

Average (Mean)

$\begin{array}{ccccc}0.01 & 0.05 & 0.26 & -0.08 & 0.11 \\ 0.14^{* * *} & 0.04 & 3.67 & 0.06 & 0.22 \\ 0.27 * * * & 0.05 & 5.02 & 0.17 & 0.38\end{array}$

High (+ 1SD)

Note: ${ }^{* * *} p<0.001$. Out. Expec. $=$ Outcome expectations

$\begin{array}{lllll}0.05 * * * & 0.02 & - & 0.01 & 0.10 \\ 0.09 * * * & 0.03 & - & 0.04 & 0.14 \\ 0.13 * * * & 0.04 & - & 0.06 & 0.21\end{array}$

$\begin{array}{lllll}0.08 * * * & 0.03 & - & 0.03 & 0.13 \\ 0.11 * * * & 0.03 & - & 0.06 & 0.17 \\ 0.14 * * * & 0.04 & - & 0.07 & 0.22\end{array}$

7.86

7.19

0.11

0.31

0.23

0.28

0.39

0.49

0.28

0.37

0.52

$\begin{array}{lll}6.79 & 0.28 & 0.52\end{array}$




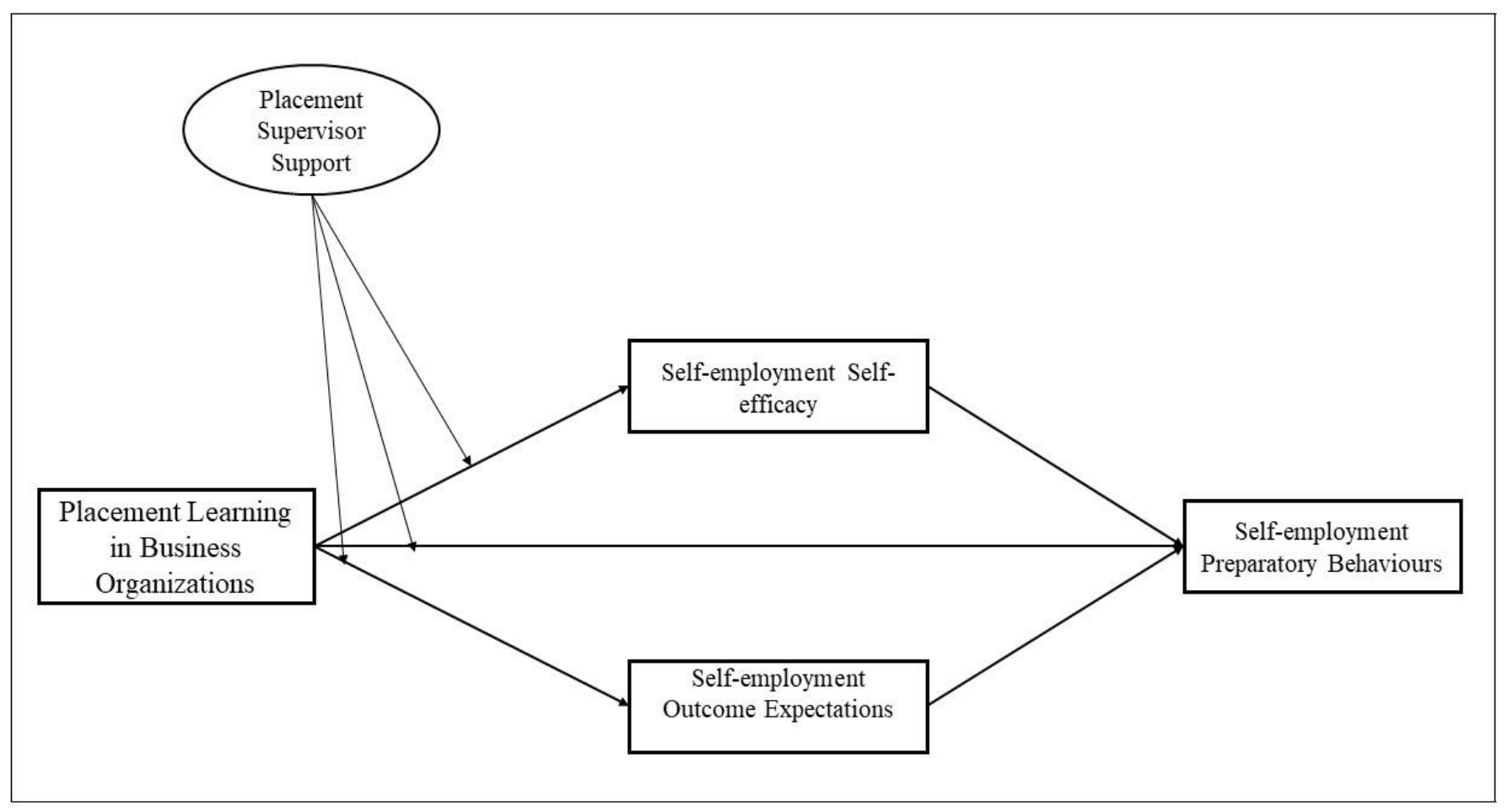

Figure 1. Conceptual model. 


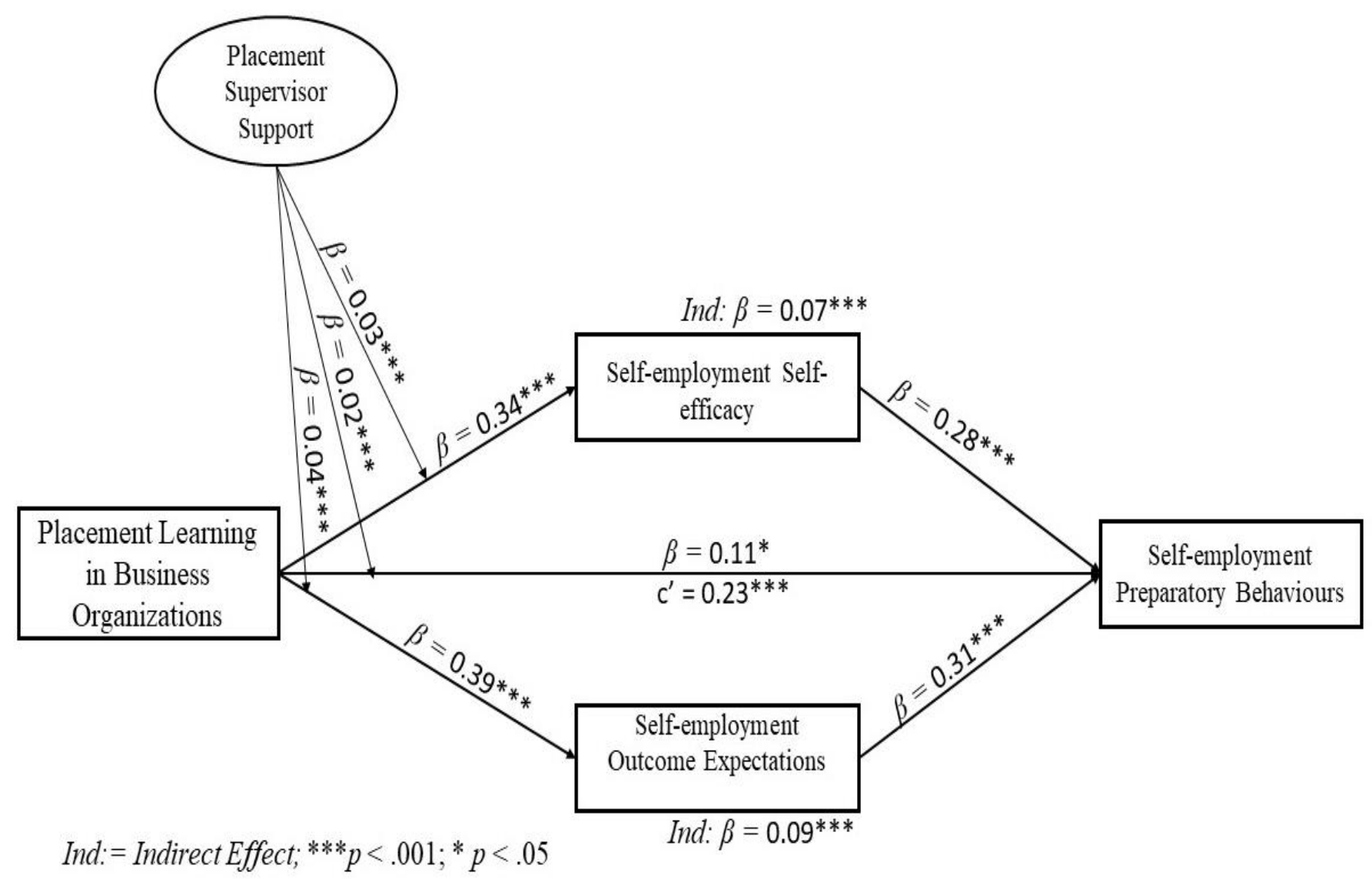

Figure 2. Results of the structural model. 


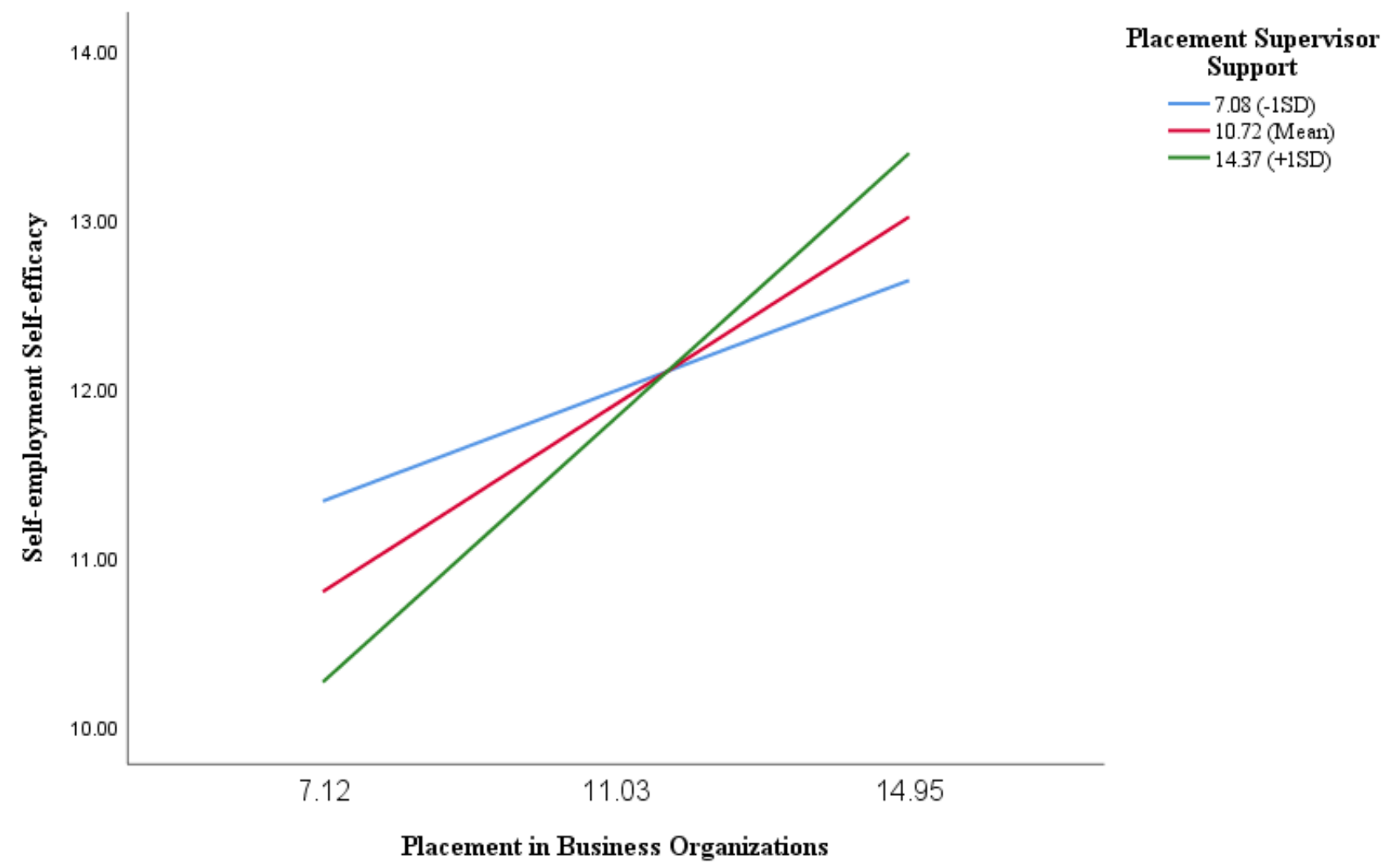

Figure 3. Interaction effect of PLBO x PSS on self-employment self-efficacy path. 


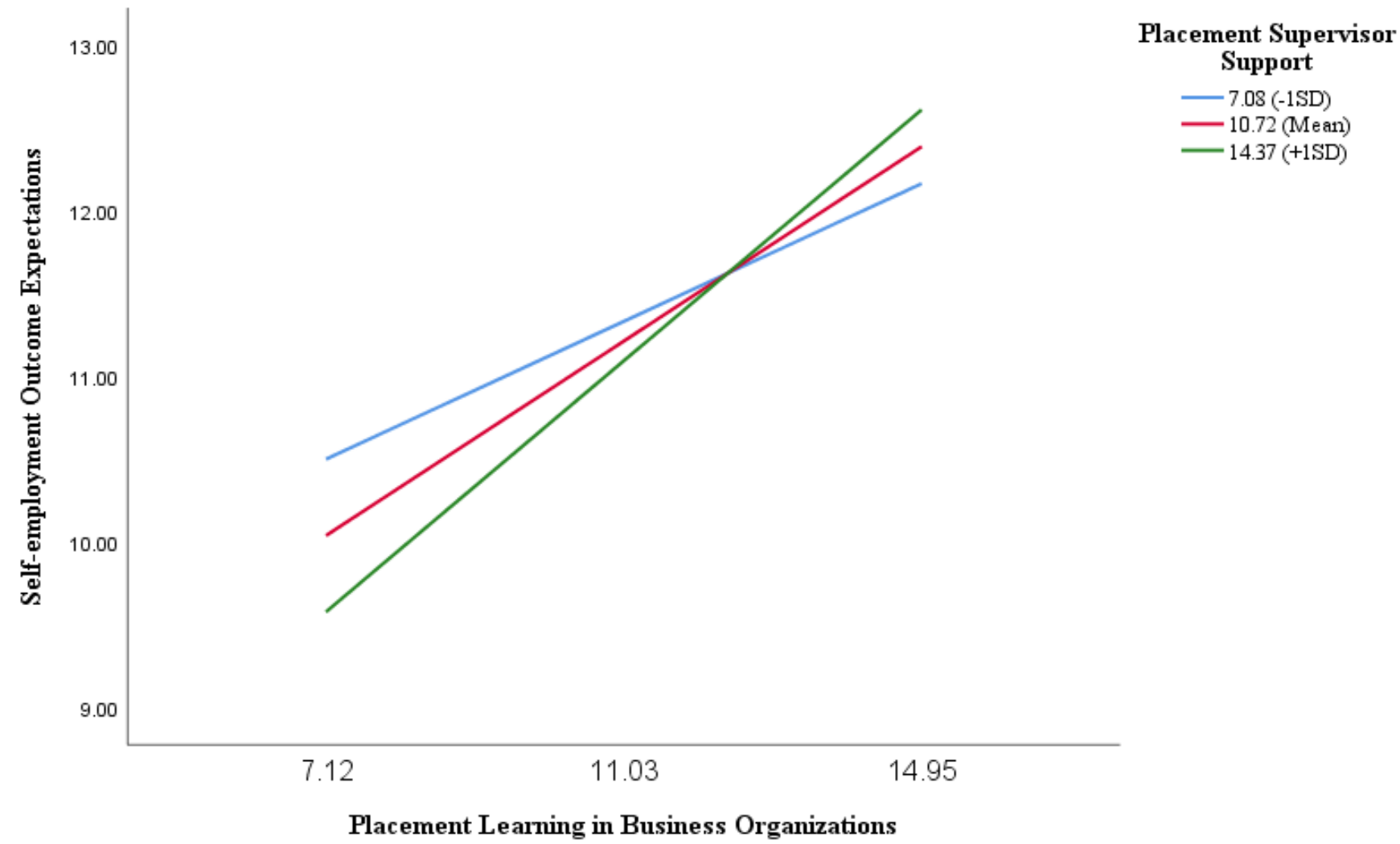

Figure 4. Interaction effect of PLBO x PSS on self-employment outcome expectations path. 


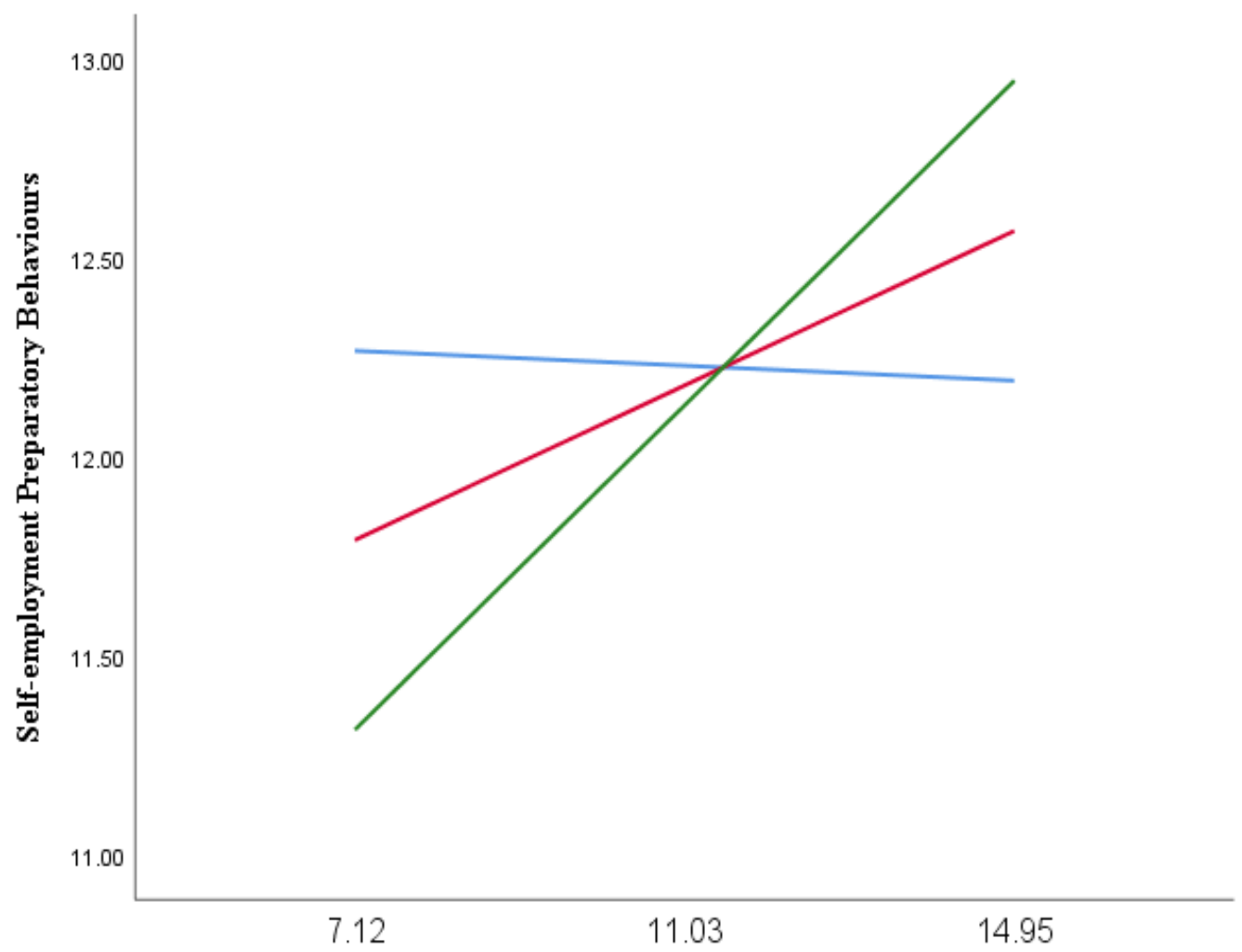

Placement Supervisor Support

-7.08 (-1SD)

- 10.72 (Mean)

$-14.37(+1 \mathrm{SD})$

Placement Learning in Business Organizations

Figure 5. Interaction effect of PLBO x PSS on self-employment preparatory behaviours path. 